\title{
Alexander Hugh Freeland Barbour, M.A., M.D., B.Sc., LL.D., F.R.C.P.E.
}

(1856-1927).

A. H. Freeland Barbour was born in Edinburgh in 1856, the youngest son of the late G. F. Barbour of Bonskeid and Gryffe. He was educated in Edinburgh, and proceeded to Edinburgh University, where he graduated M.A. and B.Sc. (in Natural Science) before entering on the study of Medicine. In 1879 he took his M.B., C.M. degree with honours, and in 1884 received his M.D., being awarded a gold medal for his thesis "On Spinal Deformity in its relation to Obstetrics."

After graduation he studied for a considerable time on the Continent, and gained a wide outlook on all that pertained to his special department, an attitude which he fostered to the end of his life, and it can truly be said that no one had a more comprehensive knowledge of contemporary obstetrics and gynæcology than he.

In collaboration with his colleague and friend, the late Dr Berry Hart, Barbour published in 1882 the well-known and indeed famous Manual of Gyncecology, a publication destined to revolutionise the study of the subject and put it firmly on a scientific basis. The book gained worldwide attention and brought great kudos to the Edinburgh Medical School. It ran through six editions, and was translated into French, Italian, Spanish, and Chinese. For many years it was the standard text-book throughout the Empire and in America.

Some years later (in 1889) he published his Atlas of the Anatomy of Labour as Exhibited in Frozen Sections (re-published in an enlarged form in 1896), which will ever be a monument of his meticulous scientific accuracy and of the painstaking industry which characterised the man. Much of the subsequent research in the anatomy and physiology of this department has been based on Barbour's work.

In recent years he published in collaboration with Professor B. P. Watson an excellent book on Gynoecological Diagnosis and Treatment, which has gained a well-deserved popularity. Many other contributions to the literature of this department have appeared from time to time from his pen, all permeated with the same originality and thoroughness which distinguished his work.

As a teacher in the University and in the School of Medicine of the P.R.S.E.-VOL. XLVII. 
Royal Colleges, he impressed his personality on the many hundreds of students who passed through his hands, in the class-room, in the wards of the Royal Infirmary, and in the Royal Maternity Hospital. He took infinite pains not only to initiate the juniors in his subject, but to stimulate the more advanced students to a fuller knowledge of the principles he had so much at heart. He had the singular faculty of inspiring enthusiasm for original research and investigation, and of encouraging scientific work. To this end he endowed a Freeland-Barbour Fellowship, both in the Royal College of Physicians and in the University. He took the deepest interest in the holders of these fellowships, and there can be no doubt that, as his former pupil, Professor B. P. Watson of New York, says :-

"There can be few who have launched on careers of usefulness so many as he."

Barbour was a past President of the Royal College of Physicians of Edinburgh, an Honorary Consulting Gynæcologist to the Royal Infirmary (after having served his full term of office as Gynæcologist), and an Honorary Consulting Physician to the Royal Maternity Hospital.

He was a Corresponding Fellow of the Royal Academy of Medicine of Turin and of the Obstetrical Society of Leipzig.

In 1906 the University of Toronto conferred on him the honorary degree of LL.D., and his own Alma Mater similarly honoured him two years ago.

When apparently in his usual health, he died suddenly and peacefully while sitting writing in his study on the 11th June 1927.

He was elected a Fellow of the Society in 1889 . J. H. F. 